\title{
Evaluation of far-field tsunami hazard in French Polynesia based on historical data and numerical simulations
}

\author{
A. Sladen ${ }^{1}$, H. Hébert ${ }^{1}$, F. Schindelé ${ }^{1}$, and D. Reymond ${ }^{2}$ \\ ${ }^{1}$ Laboratoire de Détection et de Géophysique, CEA/DASE, Bruyères-le-Châtel, BP 12, 91680, France \\ ${ }^{2}$ Laboratoire de Géophysique, CEA/Pamatai, Tahiti
}

Received: 24 October 2006 - Revised: 14 February 2007 - Accepted: 14 February 2007 - Published: 27 February 2007

\begin{abstract}
The first tsunami hazard map of French Polynesia is presented here on the basis of historical data, and numerical simulations.

French Polynesia, because of its central position in the most tsunami prone ocean, the Pacific, is strongly exposed to far-field tsunamis. As no previous study on the area had been conducted, we compiled catalogues of all the historical observations (14 events), and tide gauges records (69 marigrams). The catalogues emphasise the higher hazard associated to the Marquesas archipelago, but also the deficiency of robust data in most other parts of French Polynesia. The recourse to numerical simulations allowed us to complement the existing records, and to test tsunami scenarii over different bathymetry and topography configurations, representative of the diversity of islands in French Polynesia. The tsunami hazard map assigns a high exposure level to the Marquesas and the island of Rurutu. Other islands of the Austral, and the Gambier archipelago have a elevated level of exposure, as well as three islands of Society: Tahiti, Moorea, and Huahine. All other islands of French Polynesia are considered as moderately exposed.
\end{abstract}

\section{Introduction}

Just as the Hawaiian island chain, archipelagos of French Polynesia (FP) are exposed to trans-oceanic tsunamis because of their central position in the Pacific Ocean, where about half of all tsunamis occur. A specificity of the twentieth century is the occurrence of all the trans-oceanic tsunamis before 1965. These events were the cause of destructions and loss of many lives, while now, risk is potentially much greater with the recent and growing urbanisation of coastal areas. Considering that no attempt of tsunami hazard assess-

Correspondence to: A. Sladen

(anthony.sladen@gmail.com) ment has been done, it was important to propose at least a basic, FP-wide, evaluation.

Tsunami risk studies have often faced lack of historical data; in addition, bathymetry data are commonly of poor resolution, and restrict the use of numerical simulations to compensate this lack (Geist and Parsons, 2006). Besides, considering that FP is made of 122 low and high islands (only $4000 \mathrm{~km}^{2}$ of land) disseminated over an area about the size of Europe (more than 4 millions of $\mathrm{km}^{2}$ ) gives to understand an even more intricate task. In particular, studying FP requires the consideration of tsunamis initiated in different tectonic settings, propagation with different azimuths, and amplification through various coastal configurations.

As highlighted previously, tsunami data in FP are sparse. Notwithstanding this lack, the first aim of this study was to gather all the available historical records. This is a necessity as it can not only provide a first overview of the risk, but also help to identify areas of critical uncertainties. Once we have reached this point, it is possible to make use of numerical simulations to supply additional valuable constraints.

Some simulations have already been conducted for several bays of Marquesas (Hébert et al., 2001a,b), and placed an emphasis on the high hazard associated to this archipelago. However, these results are of almost no help in assessing the tsunami hazard in the other archipelagos, as the high islands of the Marquesas are almost unique in this part of the Pacific, having gentle bathymetric slopes, elongated bays, and are without any coral reef. Among the remaining archipelagos there are, in particular, a great number of atolls and islands surrounded by reef barriers. The impact of tsunamis on the latter have, to our knowledge, never been studied through simulation and represent one contribution of the present study.

Tsunami simulations make necessary the acquisition of expensive high resolution bathymetry and topography data, a task that we were able to conduct for only six coastal areas. Although these data are obviously insufficient to characterise

Published by Copernicus GmbH on behalf of the European Geosciences Union. 


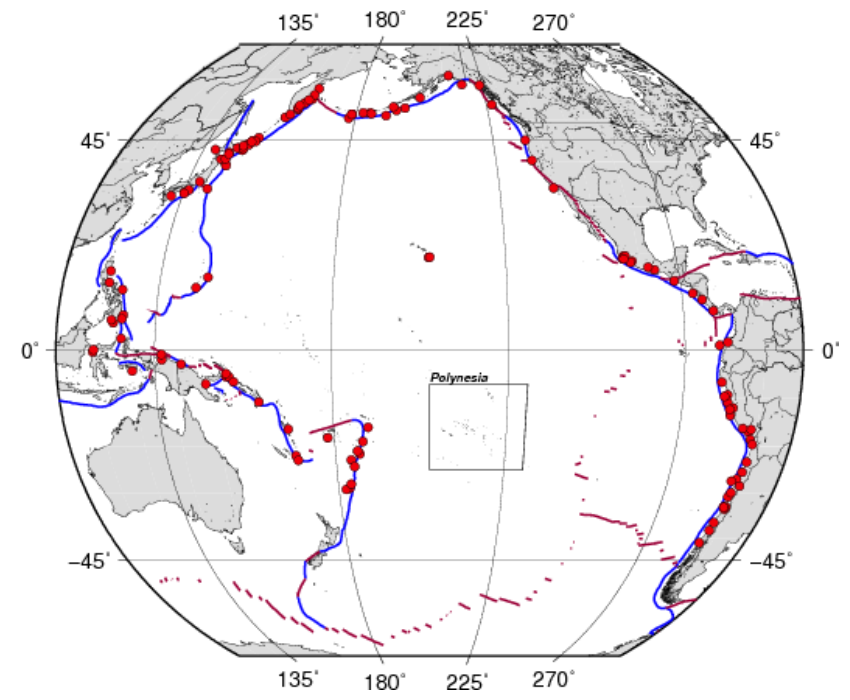

Fig. 1. Localisation of the 139 historical earthquakes which have generated a tsunami, observed or recorded, at more than $1000 \mathrm{~km}$ away from the source.

all bathymetric configurations of FP, the sites were selected to cover representative and relevant seashore environments.

Probabilistic analysis of tsunami hazard in this particular case, would require hundreds of simulations to provide a significant overview of the problem. We thus discarded the probabilistic method in favour of a deterministic type of evaluation, combining historical records and numerical simulations. As both data sets are not sufficient to provide accurate hazard levels for every islands, the analysis is only focused on the parameters affecting tsunami amplification to first order, and thus is essentially limited to groups of islands.

In this paper, our objective is to provide an overview of the tsunami hazard, going from catalogues of historical data to simulations and hazard assessment. Preceding this, we present in the next two sections, preliminary steps regarding the discrimination of the source of teletsunamis, and the quantification of historical tsunamis where available.

\section{Location of tsunamis sources and their potential}

\subsection{Catalogue of tsunamis with distant effects}

To improve our knowledge on the sources which give, or might give rise to tsunami waves in FP, we have built a catalogue of all the historical events of the Pacific recorded or observed far away from their source. This catalogue was mainly built by cross-referencing the content of the ITDB/PAC (2004) and NGDC (2006) global databases, but scientific papers were also considered for some specific events.

The source-to-site distance was fixed according to the standard definition that tsunamis are no longer regional if

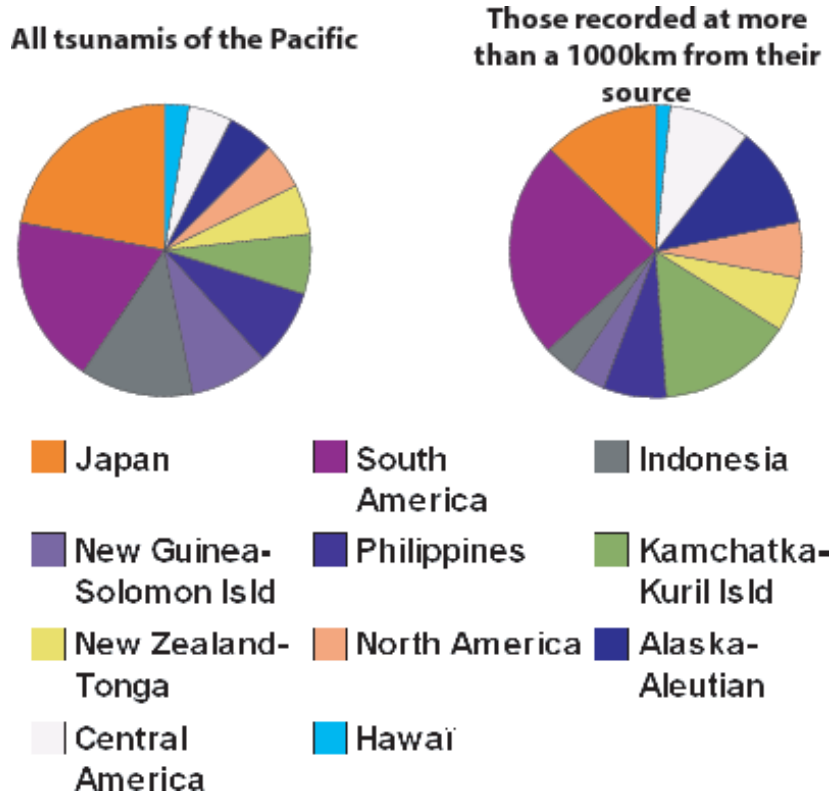

Fig. 2. Origin of all the tsunamis of the Pacific (left diagram, ITDB/PAC (2004) database), and origin of those recorded at more than $1000 \mathrm{~km}$ (catalogue presented in this study).

they are observed at more than $1000 \mathrm{~km}$ from their source. Although this distance might not suffice to fully discard local events from the database, it is still an indication that the source area has the potential to generate threatening, larger waves. An additional criteria was also applied, as only the earthquake induced tsunamis have been considered (validity criteria of 3 or 4 in the databases). This choice drastically reduces the number of events in the catalogue, and was motivated by the sparse occurrence of tsunamis initiated by alternative sources such as the collapse of volcano edifices, or the impact of comets and asteroids. Submarine landslides are yet another, more frequent kind of initiation mechanism for tsunamis. However, this type of source often have limited far-field effects and can considered less threatening to FP (Okal and Synolakis, 2004; Okal and Hébert, 2007).

As for most historical catalogues we are faced with the standard bias that old times are dominated by large events: the completeness of the catalogue is limited by the existence of written records, both at the source and at the observation point, as most coasts of the Pacific were sparsely populated before the twentieth century. In sum, 139 events are included in the database, with only 24 before 1900, and no event earlier than the 1586 Peruvian earthquake-tsunami observed in Japan. As plotted on Fig. 1, the catalogue confirms that teletsunamis are almost exclusively generated along subduction zones, and that almost all these convergent boundaries have been the source of historical events. One main exception corresponds to the great 1868 Hawaiian earthquake, which generated a tsunami detected on tide gauges in California (10 
$\mathrm{cm}$ maximum water height recorded in San Diego, USA). Beyond its very limited distant effects, this $\mathrm{Mw}=7.9$ earthquake is related to the Hawaiian hot-spot activity which is not expected to generate much larger events, mainly because larger events require longer fault systems, typically $200 \mathrm{~km}$ for a magnitude 8 .

In comparison with the whole ITDB/PAC (2004) database, our catalogue shows different proportions of events for the main regions of the Pacific rim (Fig. 2). When analysing those differences, one needs to keep in mind the limitations inherent to the fact that historical database are incomplete. However, it is tempting to interpret them as an indication of areas with a higher potential of causing destruction at far distances. This would most notably be the case of the Kamchatka-Kuril, South America, Central America and Alaska-Aleutian provinces. On the other hand, provinces of the west Pacific, going from Japan to the Salomon islands in the south, are associated with less events in our catalogue and could thus be considered less threatening to remote locations. Yet, because of the directivity effect, some subduction provinces might still pose a high hazard to some remote places located in the azimuth of maximum energy. For instance, the 1896 and 1933 Japanese earthquakes have generated large waves in Hawaii.

\subsection{Tsunamis source potential}

Due to the directivity of tsunami waves generated by thrust faults (Ben-Menahem and Rosenman, 1972), not all the subduction zones are equally expected to generate tsunamis hazardous to FP. The trench azimuth, which controls the directivity, can thus be used, in conjunction with the catalogue, to quantify the fraction of energy a subduction zone will radiate towards one particular location. To distinguish subduction provinces according to this parameter we designed three levels of classification, ranging from subduction provinces which are not expected to generate any damage, to highly hazardous ones which are directed towards FP and are expected to generate $\mathrm{Mw} \geq 9$ earthquakes (Fig. 3).

The category with provinces featuring a lower potential (refer to Fig. 3 for numbers) includes Hjort (14), Kermadec (1), Vanuatu-New-Guinea (3), Philippines to South Japan (4), Cascadia (8), and the Colombia-Ecuador segments (10). The Vanuatu and Ryukyu trenches belong to this class as island studded propagation path (effect of the Tonga and Okinawa arcs) should protect FP from large wave heights. The incipient Hjort subduction zone is another exception to the directivity criteria, as it is considered too immature to generate large thrust earthquakes (Meckel et al., 2003).

The intermediate level corresponds to fault zones with an orientation slightly offset from FP, and include segments going from central Japan to Kamchatka (6), Mexico to Central America (9), and the southern part of Peru (12). The MexicoCentral America province, although frequently shaken by $\mathrm{Mw} \geq 7$ earthquakes, has no historical records of events with magnitude above $\mathrm{Mw}=8.5$, and its potential to generate larger ones is thought to be small (Suàrez and Sànchez, 1996; Geist and Parsons, 2006). Also, numerical simulations have shown that this region and the South of Peru are not optimally oriented to threaten FP (Hébert et al., 2001a).

Subduction provinces which belong to the high potential category have both a strong directivity on FP, as well as historical records of great earthquake-tsunamis. This applies to the Tonga (2), Aleutian-Alaska (7), North Peru (11), and Chile (13) segments. The Tonga trench is an exception to this class as the $\mathrm{Mw}=8.4,17$ November 1865 earthquake is the only known event of this subduction zone to have generated a far-field tsunami observable without instruments (Okal et al., 2004). This view of the Tonga subduction is coherent with the analysis of other seismologists (Christiensen and Lay, 1988; Lundgren and Okal, 1988), and of earthquake catalogues which indicate that the vast majority of large earthquakes $(\mathrm{Mw} \geq 7)$ nucleate at depths greater than $30 \mathrm{~km}$. However, the great Indian Ocean tsunami of 26 December 2004 has demonstrated that two centuries of data are not enough to evaluate the maximum expected magnitude on a major thrust fault system. Therefore, in regard to the poor understanding of the earthquake cycle in the Tonga region, and its proximity to FP (less than $3 \mathrm{~h}$ for a tsunami to reach the main island of Tahiti), a higher potential than what the historical records alone would presuppose is attributed to this area.

Figure 3 summarises the location of the tsunami sources in the Pacific and their potential to propagate large amounts of energy in FP. Indeed, this type of map is an important contribution to the tsunami hazard assessment as it could yet provide an early indication on the low threat associated to provinces where slight, or no potential has been identified.

Up to this stage, FP was only considered as a whole and neither the source-to-archipelago path, nor the type of island was taken into account to evaluate the tsunami exposure.

\section{Tsunami impact in FP}

Before examining the interaction of tsunamis at the island scale, we recall that islands of FP can be gathered into five archipelagos, corresponding to five different alignments: Marquesas, Tuamotu, Gambier, Society and Austral (Fig. 4). These alignments of variable length ( 350 to $2500 \mathrm{~km}$ ) have a similar orientation SE-NW $\left(\mathrm{N} 110^{\circ}-\mathrm{N} 120^{\circ}\right)$ which corresponds to the absolute motion of the Pacific plate (about $11 \mathrm{~cm} . \mathrm{yr}^{-1} \mathrm{~N} 290^{\circ}$, Minster and Jordan, 1978); only the Marquesas have a different orientation of $\mathrm{N} 140^{\circ}$. These archipelagos were created by several hotspots, now located southeast of the alignments (Duncan and McDougall, 1976). In terms of island composition, Tuamotu is the only one to be exclusively made of atolls. On the other hand, Austral and Marquesas are principally composed of high islands, the latter having weak or no coral reef protection. 


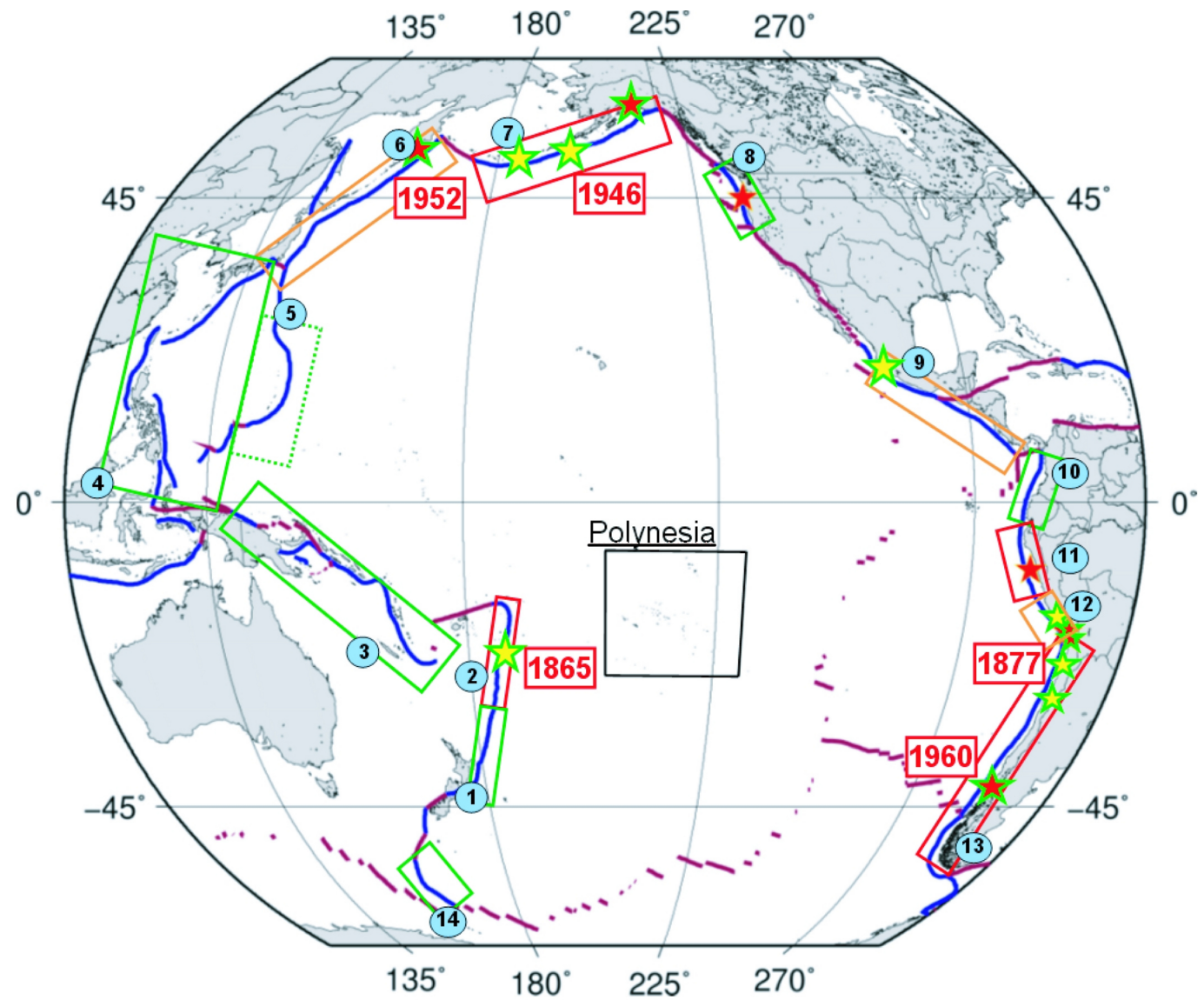

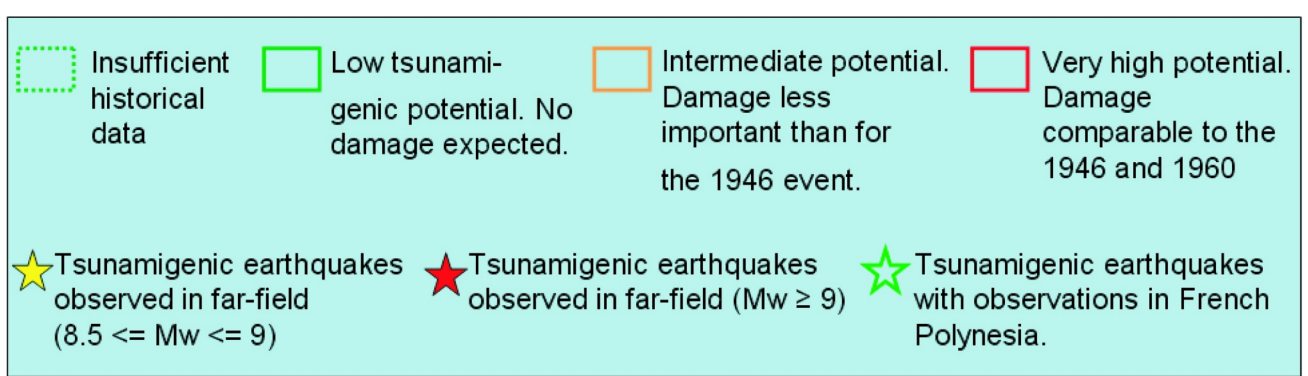

Fig. 3. Map showing the potential of the Pacific subduction zones to generate high tsunami amplitudes off-shore French Polynesia islands. Thrust plate boundaries are indicated by the blue line, while the red line locates plates boundaries with a strike-slip motion. The years in red correspond to the large historical events for which detailed simulations are conducted.

\subsection{Historical records in French Polynesia}

Historical records of tsunamis in French Polynesia only started at the turn of the nineteenth century and with the early arrival of English and French explorers. The oldest tsunami documented in the area dates back to 1806 (Candelot, 1996; Okal et al., 2002): an English voyager visiting Marquesas describes the wave phenomenon with great details, pointing out that similar events had been observed several times in the past. For the purpose of this study, only tsunamis with a clear identification of the source were considered, thus making the
1837 event the oldest one in the catalogue (Schindelé et al., 2006). Counting up to the 2001 South Peru event, 14 far-field tsunamis have been observed or recorded in FP, with as much as 6 coming from the Chilean coasts and 5 from the North Pacific. The 1946 Aleutian and 1960 South Chile tsunamis were obviously the most damaging events. The 1946 tsunami benefited from several surveys (Okal et al., 2002), and therefore provides the best overview of a tsunami interaction at the FP scale. Although it occurred many years later, the 1960 tsunami is less documented, which can be partly explained 


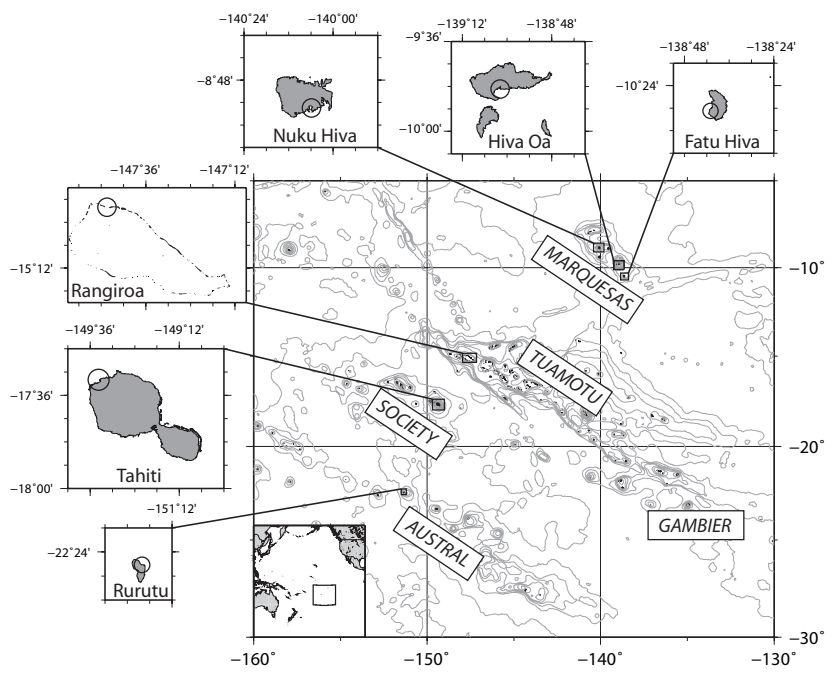

Fig. 4. Map of French Polynesia with close-up views of the six islands, or atolls, where detailed simulations have been conducted; the small circles locate the sites where the inundation has been computed. All close-up views are at scale.

by its arrival at night (Okal et al., 2002). The relatively high number of records for the 1946 and 1960 events should indeed not conceal the overall under-sampling of FP with, for instance, only three observations reported for the whole Tuamotu archipelago, which includes about two thirds of all islands of FP.

This lack of data is somewhat an indication of areas conceivably less exposed to tsunami hazard, as it could result from either weak, or no amplification, or sparse population, or a combination of both. However, drawing a conclusion from such an argument is not fully robust, and include the concept of vulnerability which is beyond the scope of this article. Thus, the conclusions drawn from historical records need to be supported by extra data such as those provided by numerical simulations (developed in next section).

As for the other teletsunamis identified in FP, excluding the 1946 and 1960 already mentioned, the number of observations is even more erratic. The list includes (Fig. 5): Kamchatka 1952, Aleutian 1957 and Alaska 1964 for the North Pacific, while in the east we identified the following list of events: Chile 1837, Peru 1868, Chile 1877, Chile 1922, Mexico and Chile 1995, and Peru 1996 and 2001. The 1865 Tonga tsunami (Okal et al., 2002) is the only event which propagated from the west. In 1999, a mass detached from a cliff of the island of Fatu-Hiva, in Marquesas, and generated a local tsunami (Hebert et al., 2002). Although this type of source is beyond the scope of this paper, the associated hazard might be important, and it would be of great interest to consider in further studies.

All in all, the whole list includes 14 teletsunamis; the details of their impact on the archipelagos will be discussed in

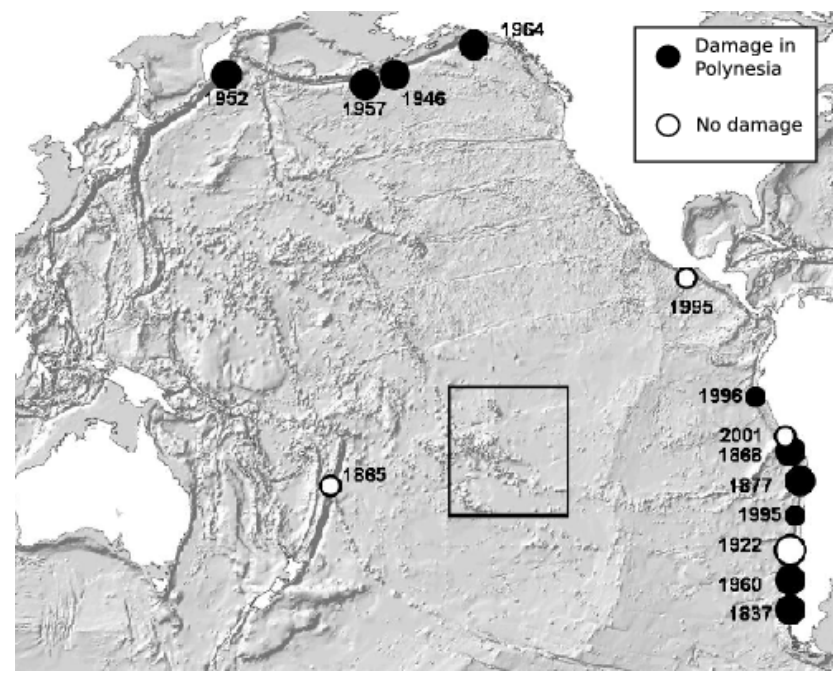

Fig. 5. Bathymetric map of the Pacific with the location and year of the source of tsunami earthquakes observed or recorded in French Polynesia.

the next section in conjunction with the numerical simulation results, and the tide gauges records.

\subsection{Tide gauge records in French Polynesia}

Because of the limited number of stations, tide gauge records can only give a limited complementary overview of tsunami history in FP. The first instrument was installed in 1958 in the bay of Matavai, Tahiti, but was subsequently stopped in 1999. Today, four instruments are in operation: Papeete (Tahiti, Society) and Rikitea (Mangareva, Gambier) both started in 1969, Tahauku (Hiva Oa, Marquesas) has been operating since 2003, and Taiohae (Nuku-Hiva, Marquesas) since 1987, although it was stopped between 1998 and 2003. Some temporary stations have also been in operation through different parts of FP. A list of all the tide gauges with a record of a tsunami was established by Schindelé et al. (2006), with a total number of 69 records corresponding to 38 different events. A maximum wave height of $1.3 \mathrm{~m}$ (trough-to-crest) was recorded in Tahiti following the 1960 south Chile earthquake of $\mathrm{Mw}=9.5$. Because most records have a very weak amplitude, only 46 can effectively be used for comparison (Fig. 6). The continuity in the recordings is very valuable to compare the impact of the tsunamis on the coast and to relate these differences to the characteristics of the source. This type of analysis will be further conducted for some archipelagos, in complement to the information provided by other types of measurement. 


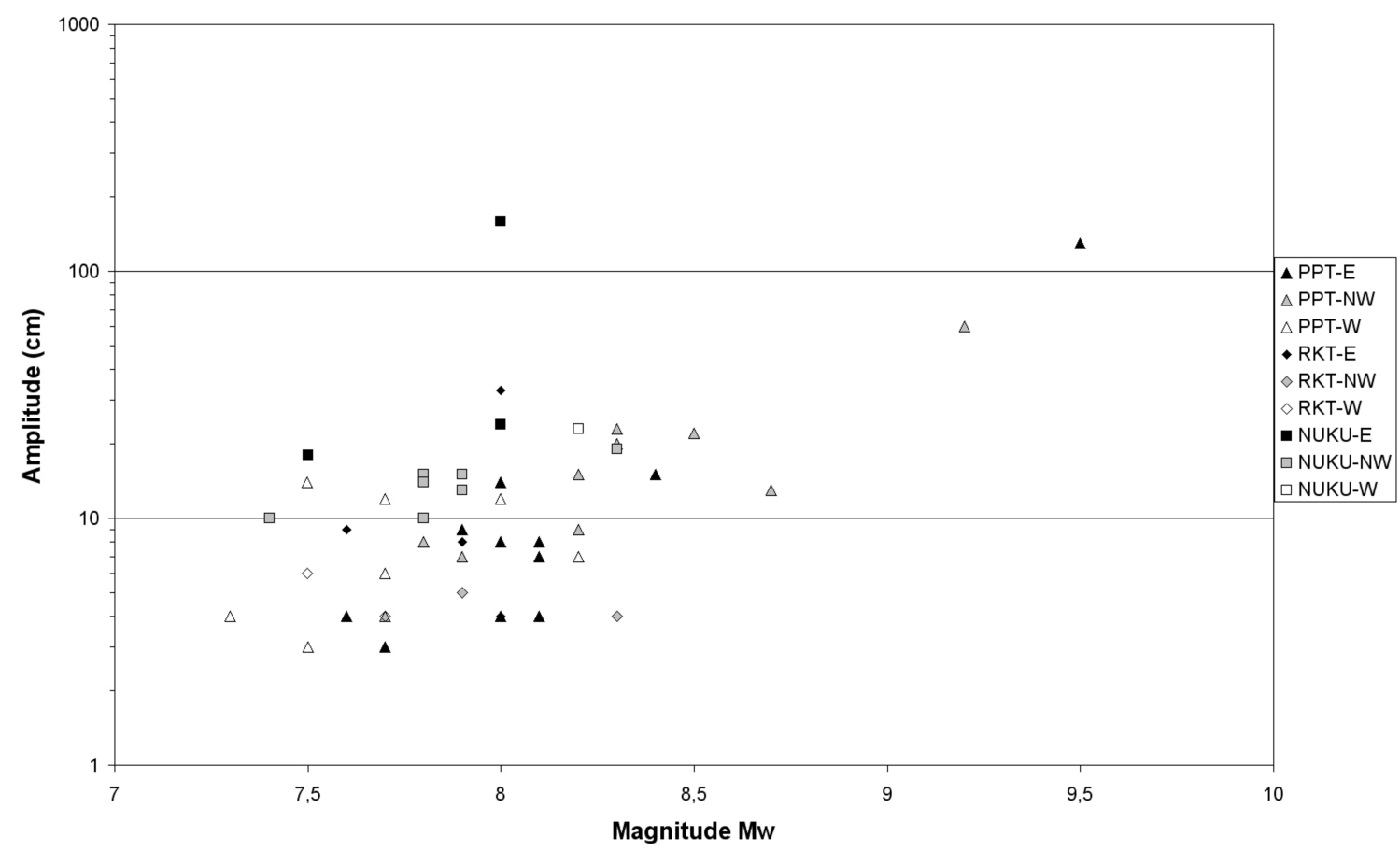

Fig. 6. Trough-to-crest wave heights, as a function of magnitude and azimuth, of the 46 main tide gauge records of earthquake induced tsunamis in French Polynesia. The tide gauge stations presented are PPT for Tahiti (Society), RKT for Mangareva (Gambier), and NUK for Nuku-Hiva (Marquesas). The records have different shades depending on the azimuth of the coming wave: from east (E: black), north (NW: grey), or west (W: white).

\section{Deterministic harzard assessment and empirical ex- trapolation}

\subsection{Defining an approach to assess tsunami hazard}

The two standard ways to deal with tsunami hazard assessment are the deterministic and probabilistic approaches. For the second, which is for instance required in the creation of tsunami insurance rate maps, the objective is to compute the yearly probability of tsunamis to exceed a given level of inundation. As aforementioned, this approach could not be applied to the case of FP because of an erratic geographical distribution of the data, and also for the reason that nowhere in FP do these data cover a large enough range of amplitudes to identify a governing amplification law: up to now, well documented probabilistic tsunami hazard studies have only been conducted on few coastal areas (e.g. Japan, Mexico) (Rikitake and Aida, 1988; Geist and Parsons, 2006). An additional objection to the use of a probabilistic approach in this study concerns the estimation of the probabilities associated with the sources: the duration of the historical catalogues is still too short to provide statistical significance, and the analysis of those data based on the theory of seismic gaps (McCann et al., 1979; Nishenko, 1985) does not seem to stand the test of time (Kagan and Jackson, 1991; Rong et al., 2003). Finally, even in the case of a well-defined earthquake probability, the question of how to take into account the nonsystematic relation between earthquake and tsunami triggering is not trivial.

The arguments just exposed emphasise the inadequacy of a probabilistic approach with the data. A purely deterministic approach, meaning to only focus on a maximum credible scenario, is neither possible given that a single scenario does not apply over such a large area and so many possible source locations.

As a consequence a hybrid empirical-deterministic approach was adopted in which both the historical data and various simulations are considered at each site, taking into account their respective pertinence and limitations. Also, no return periods for the worst case scenarii evaluated will be provided.

\subsection{Contribution of numerical simulations}

The six sites chosen for detailed simulations are presented in Fig. 4. The selection of three sites in the Marquesas archipelago is justified by the well-established higher hazard in those islands (Hébert et al., 2001a,b). Papeete harbour was compulsory in this study given that about two thirds of the population concentrate on Tahiti island, and largely dominates the economic activity of FP. Tuamotu is the widest archipelago and is only composed of atolls. To our 
knowledge, detailed simulations of tsunami impact on such low islands have never been conducted, and Rangiroa, the main atoll of Tuamotu, seemed to be an appropriate choice. Finally, Rurutu was a relevant choice as it is located south of FP, has some historical records, and no coral reef protection. Because of a lack of fine bathymetry data, Gambier is the only archipelago for which no simulation could be done. However, thanks to its very small extent (only $35 \mathrm{~km}^{2}$ ), an exposure level was derived from the existing observations, and the tide-gauge records (station RKT, Rikitea).

Following the decision to adopt a deterministic approach, and in order to simplify the analysis of the results and to limit the time of the simulations, only few sources have been tested. One of the conclusions derived from Figs. 3 and 5 was that FP is mainly concerned with tsunamis coming from either west (Tonga), north (Japan to Alaska) or east (Mexico to Chile) azimuths. The selection of sources in those areas was coherent, and turned out to be compatible with some recent historical events: 1865 for the west, 1877 and 1960 for the east, and 1946 and 1952 for the north (Fig. 3). Also, simulating historical events was a good opportunity to calibrate and validate the propagation models with historical observations, especially designed for the purpose of the simulations, but also to establish reference inundation levels in areas where there was as yet no historical records. A detailed description of the results at each site is provided by Sladen et al. (2007).

The propagation of the tsunami is computed using the classical nonlinear shallow wave equations. These equations are solved on spherical coordinates by means of a staggered grid finite-difference method (Heinrich et al., 1998; Hébert et al., 2001a). The initial water disturbance is computed using an 2D elastic dislocation (Okada, 1985), and assuming the seabottom deformation is fully and instantaneously transmitted to the above water column. For the ocean wide propagation, the global ETOPO2 (2001) data set is sufficient. Thanks to several photogrammetry data, GPS-topography field surveys, digitalised nautical charts, and multi-beam bathymetric campaigns the last levels of imbricated grids were interpolated to a resolution of $15 \mathrm{~m}$ both at sea and on land. This high level of resolution allows for detailed computations of shoaling effects and inundation. No friction coefficient is introduced in the computations. All in all, 26 grids were designed to perform the simulations on the 6 sites.

\subsection{Prescribed hazard levels and spatial resolution scale}

In order to understand the impact of tsunamis on FP, the simulations and the historical records are summarised in Fig. 7; tide gauge records are a different type of data, not appropriate for a direct comparison, and will only be discussed in the next sections. Considering the lack of records to study the influence of azimuth in more detail, and for the sake of clarity, the simulations and the historical records are only presented at the archipelago scale, and according to the three main azimuths identified previously: W, N-NW and E. To be able to compare the two data sets, the computed inundation maps are only represented by their respective maximum inundation distance and maximum run-up. Also, given that tsunami observations consist of various types of measurements - flow depth, displaced objects, river bed measurements, splash... - both the average and the maximum values are reported. Lastly, two other types of information are reported on Fig. 7 for each archipelago: the type of islands and whether or not most of them are protected by coral reefs. This information is of primary concern as they strongly control the evolution of tsunami heights at the coast.

A hazard scale has to be specified in order to have comparable exposure levels in the different parts of FP. Four levels were designed in a way similar to standard scales used in the community of tsunami research (e.g. Walsh et al., 2005): high exposure (run-up $\geq 3 \mathrm{~m}$, red), elevated exposure (runup between 1 and $3 \mathrm{~m}$, orange), moderate exposure ( 0.5 to $1 \mathrm{~m}$ run-up, yellow), or low exposure (run-up $\leq 0.5$, white) (Fig. 8).

\subsection{Evaluation of the tsunami hazard levels}

\subsubsection{Marquesas archipelago}

The configuration of Marquesas simplifies the assessment of its average exposure to tsunamis, as all the islands have a similar structure - high topography surrounded by gentle bathymetric slopes, and numerous bays -, and because most source-Marquesas propagation paths are not affected by other archipelagos, with the notable exception of the Tonga arc. Therefore, at the island scale a coherent response to tsunamis, meaning a similar hazard level, is expected, in agreement with the amplitudes reported on Fig. 7.

This derivation is supported by a fairly extensive database of historical observations, which almost all fall in the highest exposure level defined. As an illustration, the exposed coasts of the two large islands of Hiva-Oa and Nuku-Hiva, mainly bays, are well sampled by observations of tsunamis coming from the north or the east, with values of run-up systematically above $3 \mathrm{~m}$.

Numerical simulations match the observations fairly well, and confirm the archipelago should be considered at a high exposure level. However, some discrepancies remain. Most of the highest values reported in Fig. 7 are biased by the measurement of run-up next to river beds which efficiently and artificially channel the wave energy up-stream over longer distances; this complex topography interaction is certainly not correctly modelled using shallow-water wave equations over a $15 \mathrm{~m}$ resolution grid, but is sufficient to explain the underestimation of the field measurements.

Lastly, there is a near absence of observations of tsunamis coming from the west. The position of Marquesas islands north of FP and of the Tonga trench, with the Society and Tuamotu archipelago on the propagation path, certainly account for this lack of observation and the lower inundation 


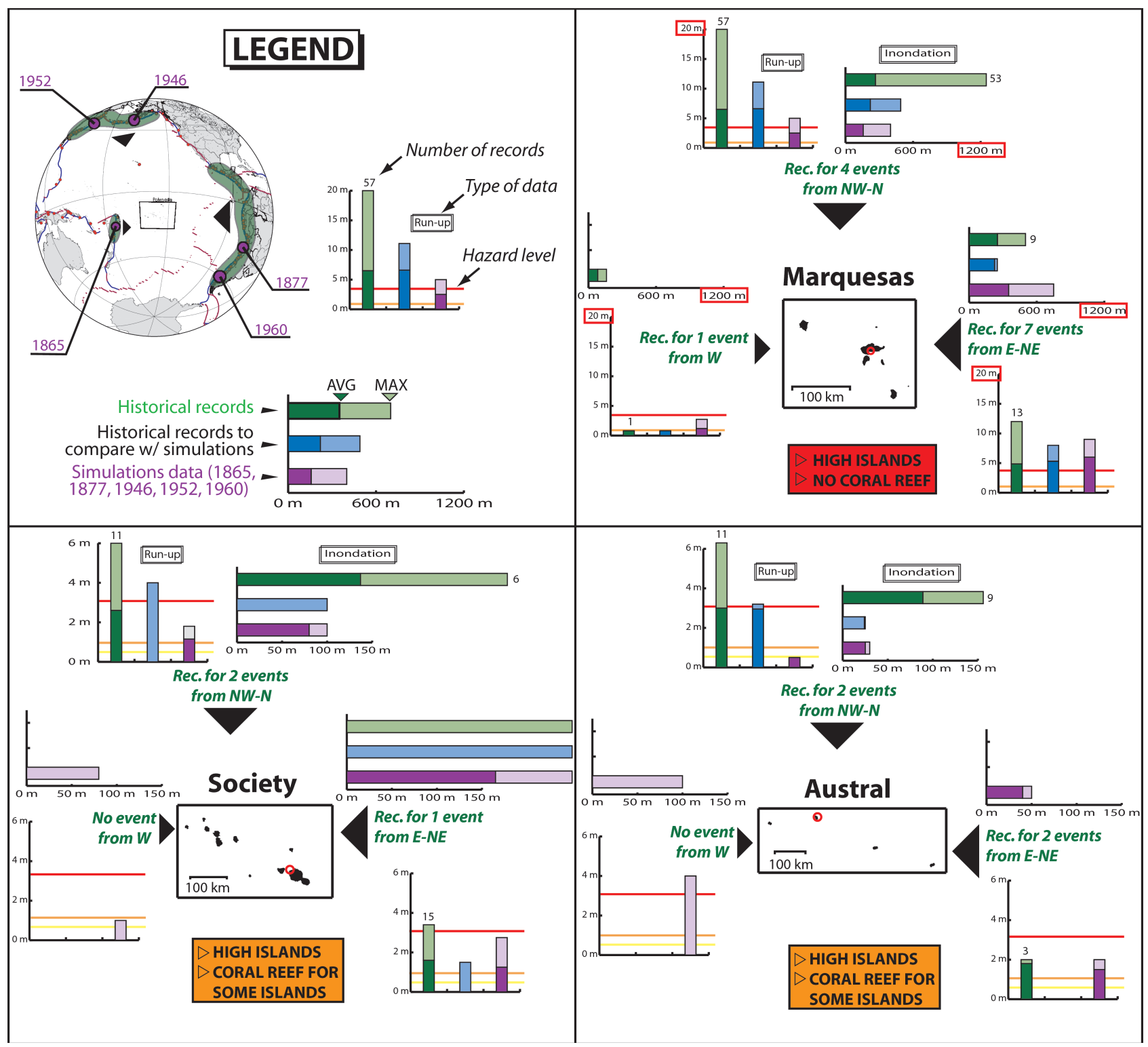

Fig. 7. Synthesis of all available tsunami data for three archipelagos of French Polynesia: Marquesas, Society, and Austral. For each archipelago, data are gathered according to the three main azimuths of impact: west for Tonga, north for Japan to Alaska, and east for Mexico down to South Chile. In each case, vertical bars indicate the run-up heights, and horizontal bars the inundation distance; the colour of these bars corresponds to, either all the historical records (green), or only the ones (blue) that can be compared with the detailed simulations of the 1865-1877-1946-1952-1960 events (purple). The coastal sites studied through detailed simulations are located by small red circles on the maps. Defined hazard levels are represented by the yellow, orange, and red lines. Note that the Marquesas bar graphs have higher scales.

heights simulated (average run-up of $1.2 \mathrm{~m}$ ). This interpretation is supported by the numerical simulations of Hébert et al. (2001b), which point out that only sources in the northern end of the Tonga arc are hazardous to Marquesas.

Tide gauge records provide another means to study the influence of the azimuth. However, useful records in the Marquesas are limited to the station installed in Taiohae bay, on the island of Nuku-Hiva. The plot of trough-to-crest wave height measurements as a function of magnitude for this station (Fig. 6) reveals a systematic lower amplitude of tsunamis coming from the north compared to the east and west directions. Although in the latter case, there is only one measurement that might not be representative of a systematic trend, just as the bay of Taiohae might not be representative of the whole Marquesas. In sum, it is difficult to derive a trend for the effect of source localisation, but the average level of 
run-up is far above the highest hazard level whatever the azimuth considered (Fig. 8).

The number of historical data even allows us to suggest approximative return periods. In addition to the three major events which have affected the Marquesas archipelago (1837, 1946 and 1960), the tsunami waves have exceeded $3 \mathrm{~m}$ of run-up five times during the last 130 years: in 1877, 1922, 1957, 1964 and 1995 (Schindelé et al., 2006 and references therein). This gives an average return period of about 20 to 30 years for tsunamis in Marquesas.

\subsubsection{Society archipelago}

Characterisation of the hazard level of the Society archipelago is more complex due to the different island configurations.

For the main island of Tahiti, and including the numerical simulations at the Papeete harbour, the exposure is elevated with run-up heights in the range of 1 to $3 \mathrm{~m}$ (Fig. 7) for the three main historical events (1837, 1946 and 1960). However, major events, like in 1946 and 1960, have produced higher run-up in some places, and a higher level of exposure might be required for the hazard assessment over longer periods of time (in the order of a century). All the average run-up values presented in Fig. 7 fall in the elevated level of exposure (orange).

Numerical simulations are compared with the historical records and, in the case of the Papeete harbour, they allow to estimate the influence of the recent man-made works on the tsunami exposure. Records of tsunamis coming from the north, mostly from the 1946 event, are underestimated by the simulations by about $2 \mathrm{~m}$, and suggest that the building of the harbour in the sixties offers a better protection to tsunamis. However, the near absence of data for tsunamis coming with different azimuths prevents the generalisation of this result: Papeete was already a natural harbour before the building of a sea wall on the reef barrier; thus, it is not certain that the new structure shatters all incoming long waves, and does not simply focus the energy in a different way.

Another purpose of the simulations was to quantify the hazard level associated to tsunamis initiated along the Tonga trench as they did not provide significant historical records. Run-up heights have been computed for the 1865 Tonga event, whose magnitude was estimated at $\mathrm{Mw}=8.3$ by Okal et al. (2004): they almost provide the same level of hazard as other azimuths, though the magnitude is the smallest of all sources tested.

In spite of not having enough historic records to derive an exposure level for the other islands of the Society archipelago, it can be assumed that these islands are better protected from tsunamis by their much larger lagoons. Only Moorea and Huahine islands have a similar reef to Tahiti's, and are therefore assigned an elevated exposure level.

To sum up, a moderate hazard level is assigned to the islands of Society (for coastlines distant from the pass), and an elevated level to the islands of Tahiti, Moorea and Huahine (Fig. 8).

\subsubsection{Austral archipelago}

Austral islands have been unevenly affected by the main tsunamis of the twentieth century. For the 1946 event, the field survey of Okal et al. (2002) revealed important run-up values in Raivavae, Tubuai, and even more important in Rurutu where run-ups of $3 \mathrm{~m}$ have been reported. It is interesting to note that the head of the meteorological department at that time did not mention any damage in his report of 1 May 1946 (Polynesian Territory archives), with the exception of a dock displaced in Rurutu. These differences modify the perception of the event and emphasise the importance of detailed surveys. Thus, the 1946 records show that Rurutu is more exposed, most certainly as it is also the only island of Austral without a lagoon.

The numerical simulations of historic tsunamis in the bay of Moerai, on the north-eastern coast of Rurutu (Fig. 4), cannot explain the reported run-up and inundation distances (Fig. 7). We think this model-data mismatch is related to the complex coastal topography along Moerai's coastline, and the inability of the simulation code to model its inundation properly: in this part of the island, the sea-land transition is characterised by a fringing reef (about $50 \mathrm{~cm}$ deep), and a steep bank reaching 2 to $3 \mathrm{~m}$ in height over a distance smaller than a grid cell $(15 \mathrm{~m})$.

Indeed, this special coastal topography could help explain the apparent paradox between the almost absence of effects reported, and the elevated run-up heights measured during the recent field survey: a tsunami wave, such as the 1946's, lost a large amount of its energy going across the bank, solely generating inundation over short distances (about a few tenth of meters) as reported by Okal et al. (2002). Yet, in this ana lysis, we did not mention the possible effect of the modified coastal environment (the road running along the bank did not exist at the time of the tsunami), nor the effect of tides whose amplitude is estimated at $1.2 \mathrm{~m}$ at the time of the 1946 event.

Although the simulation of the 1946 event cannot explain the high run-up values observed, the results can be used to compare the relative effects of other simulated events. In particular, the 1877 and 1960 tsunamis produce run-up values higher by almost $2 \mathrm{~m}$, and even $3 \mathrm{~m}$ in the case of the 1865 Tonga tsunami. Hence, on average, it seems that the exposure level is higher in Austral than in Society. Considering all these elements, we derived that Rurutu is highly exposed, while other islands of Austral have an elevated level of exposure (Fig. 8).

\subsubsection{Tuamotu archipelago}

With the exception of a $1.8 \mathrm{~m}$ run-up reported in Takaroa, there is no historical record for the atolls of Tuamotu, which 


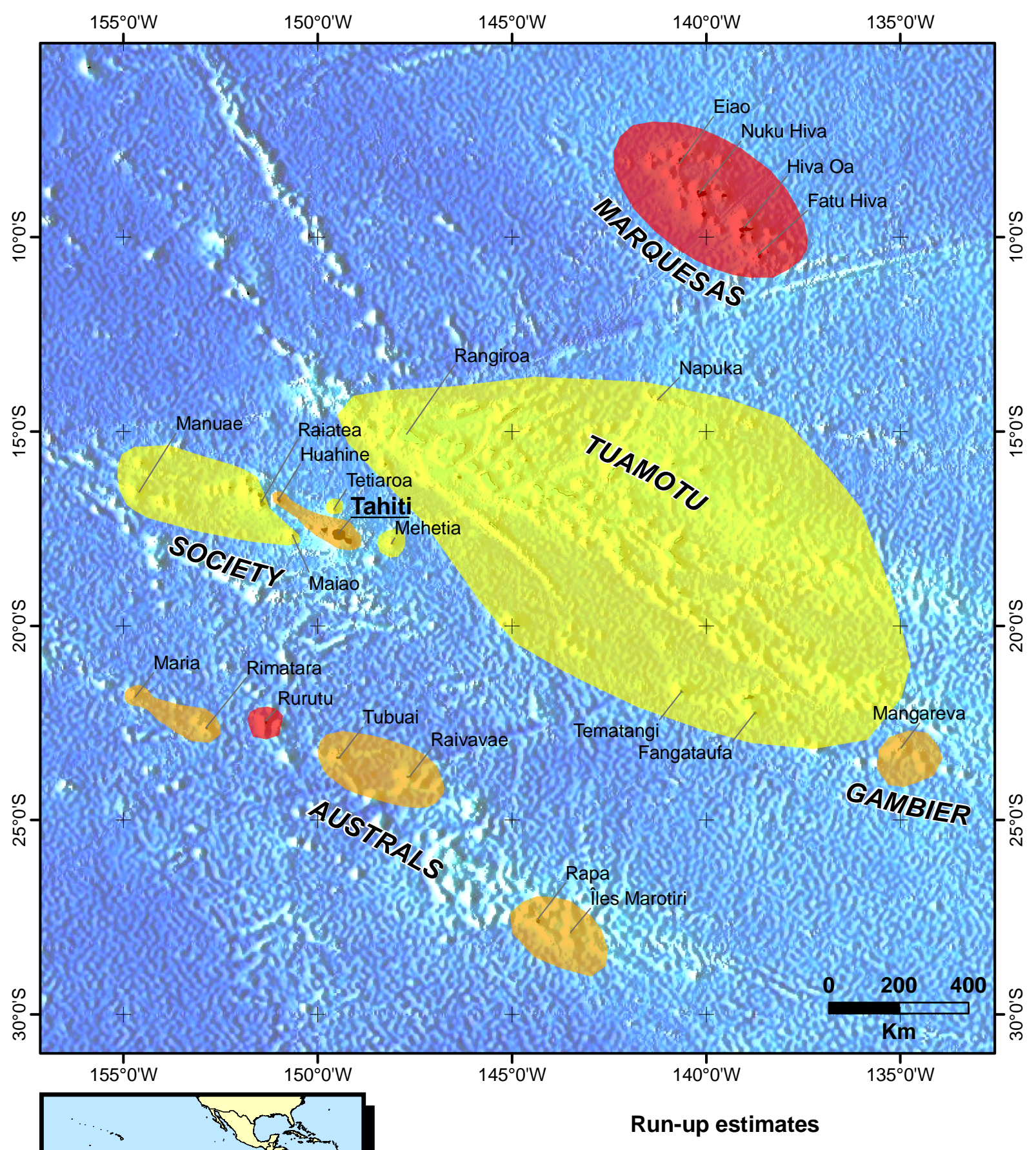

Run-up height
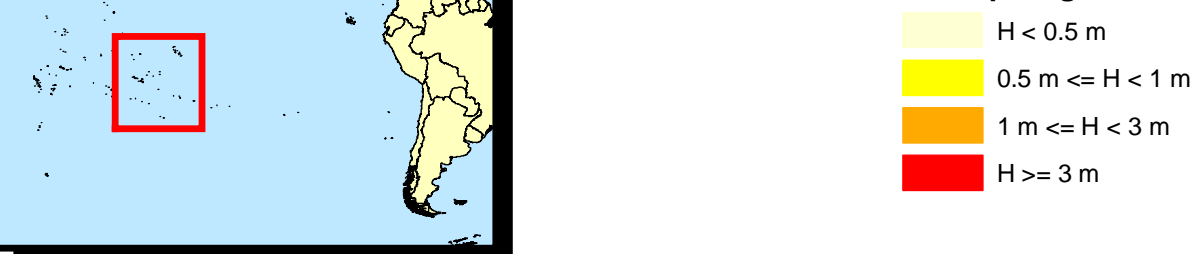

Fig. 8. Estimated tsunami hazard in French Polynesia. The hazard scale has four levels: low (white), moderate (yellow), elevated (orange), and high exposure (red). 
suggests a low exposure. The heights observed for the recent moderate tsunamis were on the order of the off-shore amplitudes, and consolidate the idea of a very low amplification of tsunamis by this type of island. This almost negligible amplification can be explained by very long waves relative to the length of the bathymetric slope. On the other hand, low runup heights can also be explained by reflection or breaking on the atolls, which is more pronounced for shorter waves. Nevertheless, it is of primary importance to check the compatibility of this assertion with numerical simulations. On the Avatoru pass, Rangiroa atoll, the simulations show fairly high run-up heights, between 0.8 and $2 \mathrm{~m}$ (Fig. 9). These values are the maximum amplitudes computed and correspond solely to the outer part of the atoll; the tsunami attenuates very rapidly through the pass and only very low amplitudes remain inside the atoll $(\leq 1 \mathrm{~m})$, while on the sea side the fairly steep beach precludes any significant inundation.

Therefore, a moderate hazard level is assigned to the Tuamotu archipelago (Fig. 8) with the possibility of a elevated level of exposure for the areas around the pass.

\subsubsection{Gambier archipelago}

Gambier are the closest islands of FP to the South American subduction zone. Actually, Gambier is only a small group of 4 main high islands enclosed in a $35 \mathrm{~km}^{2}$ barrier reef. This specific configuration suggests that the archipelago is fairly well protected. However, there were observations of the 1946 and 1964 tsunamis, while the Gambier were very much affected by the 1960 event. The higher hazard posed by tsunamis originating from the South American coast is supported by some records at the Rikitea tide gauge station (Fig. 6).

The exact level of exposure could not be evaluated through numerical simulation as no detailed bathymetry data were available. Nevertheless, the historical data aforementioned stress the idea that run-up of a few meters cannot be completely excluded, and that Gambier should be considered at an elevated exposure level (Fig. 8).

\section{Conclusion}

Thrust earthquakes are the main source of trans-oceanic tsunamis in the Pacific, and represent one of the major natural hazards for FP. The stakes are high, and this study is the first attempt to provide an estimate for this type of hazard. Hence, the starting point of this work was to compile all the historic observations (14 events) and measurements (69 marigrams) of tsunamis in the five archipelagos constituting FP. These catalogues are quite poor as, on top of the standard requirements of tsunami hazard assessment, FP calls for the consideration of an extremely large area, a wide variety of bathymetric configurations, and a high number of azimuths for the incoming long waves. The recourse to nu-

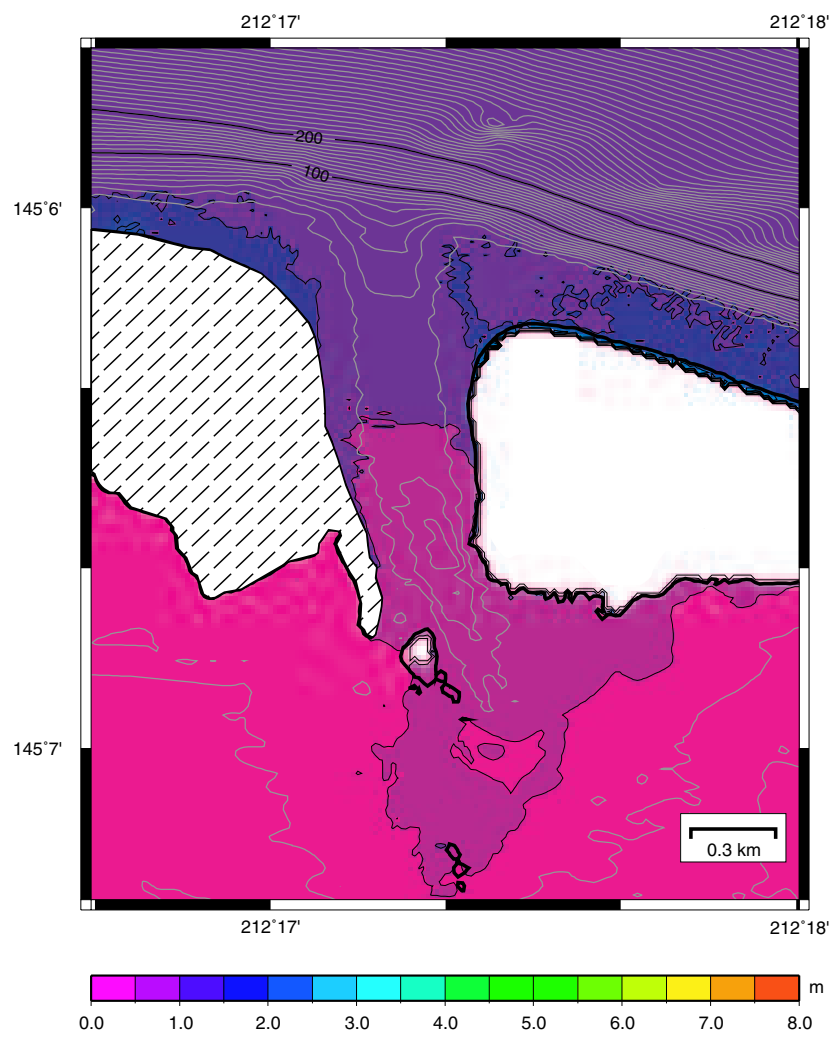

Fig. 9. Map of maximum inundation for the pass of Avatoru (Rangiroa atoll, Tuamotu, see Fig. 4) computed for all the simulations (1865, 1877, 1946, 1952 and 1960 earthquake). The thick black line corresponds to the original coastline. The left part of the pass is hatched as no detailed topography data was acquired on this side.

merical simulations was made in order to supply additional valuable data, although only six sites could be tested because of data availability. The main consequence of this limitation and the low number of run-up measurements, is that the final map mainly lays out the tsunami hazard at the archipelago scale. The cross-analysis of the different data sets have led us to derive the following levels of exposure: a high level (run-up above $3 \mathrm{~m}$ ) for the Marquesas archipelago and $\mathrm{Ru}$ rutu island, an elevated exposure level for the other islands of Austral, the Gambier, and the islands of Tahiti, Moorea, and Huahine (Society). Other Society islands, and the Tuamotu archipelago are moderately exposed.

No significant improvements are expected in the recording of events in FP in a near future. Hence, it is of primary importance to perform more detailed simulations over smaller areas, and to develop new tools to extrapolate the results of coarse simulations to the shore. However, the former solution is strongly dependent on the availability of fine bathymetry and topography data, and leads us to the conclusion that efforts should be mainly directed towards the second option. 
Acknowledgements. This study was supported by the French government, the French Polynesian territory administration, and the BRGM, as part of the natural hazard assessment programme ARAI. Most figures were created using the Generic Mapping Tools package (Wessel and Smith, 1991). We thank C. B. Harbitz and two anonymous reviewers for their careful reviews that contributed to improve our manuscript.

Edited by: E. Pelinovsky

Reviewed by: C. B. Harbitz and two other referees

\section{References}

Ben-Menahem, A. and Rosenman, M.: Amplitude patterns of tsunami waves from submarine earthquakes, J. Geophys. Res., 77, 3097-3128, 1972.

Candelot, J.: Tai Toko ! ou l'imminence d'un cataclysme, Association des historiens et géographes de Polynésie française et Centre territorial de recherche et de documentation pédagogique de Polynésie française, Pirae (Tahiti), 1996.

Christiensen, D. and Lay, T.: Large earthquakes in the Tonga region associated with subduction of the Louisville Ridge, J. Geophys. Res., 93(B11), 13 367-13 389, doi:10.1029/88JB03052, 1988.

Duncan, R. and McDougall, J. L.: Linear volcanism in French Polynesia, J. Volcanol. Geotherm. Res., 1, 197-227, 1976.

ETOPO2: 2-minute Gridded Global Relief Data, Tech. rep., National Geophysical Data Center, U.S. Department of Commerce, http://www.ngdc.noaa.gov/mgg/fliers/01mgg04.html, 2001.

Geist, E. and Parsons, T.: Probabilistic analysis of tsunami hazards, Nat. Hazards, 37, 277-314, 2006.

Hébert, H., Heinrich, P., Schindelé, F., and Piatanesi, A.: Far-field simulation of tsunami propagation in the Pacific Ocean: impact on the Marquesas Islands (French Polynesia), J. Geophys. Res., 106(C5), 9161-9177, doi:10.1029/2000JC000552, 2001a.

Hébert, H., Schindelé, F., and Heinrich, P.: Tsunami risk assessment in the Marquesas islands (French Polynesia) through numerical simulation of generic far-field events, Nat. Hazards Earth Syst. Sci., 1, 233-242, 2001b.

Hebert, H., Piatanesi, A., Heinrich, P., Schindele, F., and Okal, E.: Numerical modeling of the September 13, 1999 landslide and tsunami on Fatu Hiva Island (French Polynesia), Geophys. Res. Lett., 29, doi:10.1029/2001GL01374, 2002.

Heinrich, P., Schindelé, F., Guibourg, S., and Ihmlé, P. F.: Modeling of the February 1996 Peruvian tsunami, Geophys. Res. Lett., 25(14), 2687-2690, doi:10.1029/98GL01780, 1998.

ITDB/PAC: Integrated Tsunami Database for the Pacific. Version 5.12 of $31^{\text {st }}$ December 2004, Tsunami Laboratory, ICMMG SD RAS, Novosibirsk, Russia, 2004.

Kagan, Y. Y. and Jackson, D. D.: Seismic gap hypothesis: Ten years after, J. Geophys. Res., 96, 21 419-21 431, 1991.

Lundgren, P. and Okal, E.: Slab decoupling in the Tonga Arc: the 22 June 1977 earthquake, J. Geophys. Res., 93, 13 355-13 366, doi:10.1029/88JB00452, 1988.
McCann, W. R., Nishenko, S., Sykes, L., and Krause, J.: Seismic gaps and plate tectonics: Seismic potential for major boundaries, Pure Appl. Geophys., 117, 1082-1147, 1979.

Meckel, T. A., Coffin, M., Mosher, S., Symonds, P., Bernardel, G., and Mann, P.: Underthrusting at the Hjort Trench, AustralianPacific plate boundary: Incipient subduction?, Geochem. Geophys. Geosyst., 4, 1099, doi:10.1029/2002GC000498, 2003.

Minster, J. and Jordan, T.: Present day plate-motions, J. Geophys. Res., 83, 5331-5375, 1978.

NGDC: Tsunami Database, National Geophysical Data Center Online Catalogs, NOAA/NESDIS, http://www.ngdc.noaa.gov/seg/ hazard/tsu_db.shtml, 2006.

Nishenko, S. P.: Seismic potential for large and great interplate earthquakes along the Chilean and southern Peruvian margins of South America: A quantitative reappraisal, J. Geophys. Res., 90, 3589-3616, 1985.

Okada, Y.: Surface deformation due to shear and tensile faults in a half-space, Bull. Seismol. Soc. Am., 75, 1135-1154, 1985.

Okal, E. and Hébert, H.: Far-field modeling of the 1946 Aleutian tsunami, Geophys. J. Int., in press, 2007.

Okal, E. and Synolakis, C.: Source discriminants for near-field tsunamis, Geophys. J. Int., 158, 899-912, 2004.

Okal, E., Synolakis, C., Fryer, G., Heinrich, P., Borrero, J., Ruscher, C., Arcas, D., Guille, G., and Rousseau, D.: A field survey of the 1946 Aleutian tsunami in the far field, Seism. Res. Lett., 73, 490-503, 2002.

Okal, E., Borrero, J., and Synolakis, C.: The earthquake and tsunami of 1865 November 17: evidence for far-field tsunami hazard from Tonga, Geophys. J. Int., 157, 164-174, 2004.

Rikitake, T. and Aida, I.: Tsunami hazard probability in Japan, Bull. Seismol. Soc. Am., 78, 1268-1278, 1988.

Rong, Y., Jackson, D. D., and Kagan, Y. Y.: Seismic gaps and earthquakes, J. Geophys. Res., 108, 6-1, doi:10.1029/2002JB002334, 2003.

Schindelé, F., Hébert, H., Reymond, D., and Sladen, A.: L'aléa tsunami en Polynésie française: synthèse des observations et des mesures, C. R. Geosci., 338(16), 1133-1140, 2006.

Sladen, A., Hébert, H., and Schindelé, F.: L'aléa tsunami en Polynésie française: apports de la simulations numérique, C. R. Geosci., in press, 2007.

Suàrez, G. and Sànchez, O.: Shallow depth of seismogenic coupling in southern Mexico: implications for the maximum size of earthquakes in the subduction zone, Phys. Earth Planet. Inter., 93, 53-61, 1996.

Walsh, T. J., Titov, V. V., Venturato, A. J., Mofjeld, H. O., and Gonzalez, F. I.: Tsunami hazard map of the Anacortes-Whidbey island area, Washington: modeled tsunami inundation from a cascadia subduction zone earthquake, Report 1, Washington Division of Geology and Earth Resources, http://www.dnr.wa.gov/ geology/pdf/ofr05-1.pdf, 2005.

Wessel, P. and Smith, W. H. F.: Free software helps map and display data, Eos Trans., AGU, 72, 1991. 